\title{
Demographic Scenario of India: Opportunities and Challenges
}

\author{
Pramod Pandurangrao Lonarkar ${ }^{*}$
}

\begin{abstract}
India, the second most populous country in the world has undergone several demographic changes. The current age composition shows high quantum of young population. This is an opportunity for the country if appropriate policy measures are taken. The objective of this paper is to focus on the timely trend of demographic transition to highlight the threshold time limit of opportunity and challenges ahead. A long time series data of around 150 year has been analyzed to derive conclusions and to create supportive background for policy formulation. The study found that India is in the third stage of demographic transition which will last during 2065 to 2070, where India's population will be at its peak. But the threshold limit of the increasing working age population will be 2030 , with around $64 \%$ working age people and lowest dependency ratio. This paper shows that number of old female dependents will increase in the transition process. This paper also indicates the need for policy formulation to address the short term and long term opportunities and challenges.
\end{abstract}

Keywords: Demographic Transition, Demographic Dividend, Age Composition, Aging, Dependency Ratio, Literacy, Fertility, Mortality

"School of Social Sciences, S.R.T.M. University, Nanded, Maharashtra, India; prmodlonarkar@gmail.com 


\section{Introduction}

Initial writings on the growth of population were pessimistic in nature. The mismatch in population and food production addressed by Malthus is not materialized. Rather it is observed that the trend of population and food production is moving in same direction without causing to any disaster in recent decades. This optimistic picture has changed the overall mind set of the demographers and policy makers to think on the opportunities hidden in demographic structure during the process of demographic transition. So the opportunity in the form of 'Demographic Dividend' is getting special concern in resent research sphere. Achieving demographic dividend is not an automatic process. It needs proper policy action to reap the opportunity of economic growth. So there is a strong requirement to analyze the current and future status of population to create proper background for policy formulation. Especially for countries like India where there is a wide dissimilarity in states.

India the world's second largest populous country has under gone through several changes in its demographic composition. The demographic transition of country shows a steep fall in mortality rate and improved longevity. The movement of mortality and longevity added more and more persons to its total population.. So the number of persons added in India during last decade is more than all other countries in the world except China, USA, Indonesia, Brazil and Pakistan. This is caused by improved health care technologies and access to health care all over country and the world also helped to improve longevity. Similarly sanitation, increase in food supply and improved educational status of women and men. The estimated population by the United Nations Population Division shows that India will overtake China's population close to 2022 and there will be significant changes in future age composition in India.

A keen look at state level shows different demographic situations. Nearly half population of the country is clustered in five states namely Uttar Pradesh, Maharashtra, Bihar, West Bengal and Andhra Pradesh. These states are the population change makers; 
whose demographic situation should be the prior concern for the policy makers.

The changing composition of age will bring some opportunities as well as challenges for Indian economy. If country maximally utilizes its working age population it will become the opportunity in the form of demographic dividend. Similarly the increasing dependency ratio and several other problems of ageing are the challenges for India. So this paper will discuss the phase of India's demographic transition, its current demographic scenario, and emerging age composition of country, to shade a light on the opportunities and challenges ahead.

\section{Objective}

This study pertains to two main objectives. The first objective of this paper is to present current demographic scenario of India. Second objective is to focus on opportunities and challenges for India based on long projected time series data.

\section{Data Source and Method}

The nature of this study is analytical one where analysis of current scenario will be made on the basis of Census 2011 data with special focus on bigger states of the country. To focus on demographic opportunities and challenges, a long time series data published by U.N. population division is used. The estimated data of U.N. population division may or may not be exactly matched with the data published by census authority of India, but it is valuable to analyze the trend for future period.

\subsection{Current Demographic Scenario of India}

The initial growth of India's population was very slow, so it took very long period (seventy years) to double its population from 1901 to 1971. Later on the growth has been picked up and it took around thirty years to double its population during 1971 to 2001. Further the trend of population growth is falling continuously after nineteen eighties. But still there is huge addition of the number of persons in the total population every year. Following is the current demographic scenario of India in brief. 


\section{Population Growth}

As per the 15th National census survey conducted by Census Organization of India, the population of India in 2011 is counted as 121 crore, of which $69 \%$ are living in rural area and $31 \%$ are living in urban areas of the country. During the last decade from 2001 to 2011 India's population has grown by $17.7 \%$. The population added during last decade is 18.19 crore persons, which is more than the population of Maharashtra state. It is important to mention that India accounts only 2.4 percent of world's surface area where as it comprises 17.5 per cent of the world population which is much closer to China which has 19.4 per cent of the world's total population. In contrast to this, USA accounts 7.2 percent of world's surface area and it has only $4.5 \%$ of world's population. As per the census of 2011 the decadal growth of population in rural area is reported 12.3 percent where as it is 31.8 percent in urban area. Data on states shows that Uttar Pradesh, Maharashtra, Bihar, West Bengal and Andhra Pradesh are most populous states of the country which accounts nearly $50 \%$ of India's population. The two most populous states namely Uttar Pradesh and Maharashtra account for $26 \%$ of India's total population. Uttar Pradesh is having large rural population (18.6\%) of the country and Maharashtra has highest urban population $(13.5 \%)$ of the country. The data shows that urban population has increased by 3.4 percentage points over its share in last census. The higher growth of population in urban areas led to high population density and many civic problems. The word density of population reflects the concentration of population in particular area. As per census 2011 population density for India is 382 persons per square kilometer which was 325 in 2001. The density in Indian states is very much diverse like Delhi, Chandigarh, Puducherry, Daman and Diu and Lakshadweep are the high density states having range of density ranges between 2015 persons to 11,320 persons per square kilometers.

Among the bigger states, Bihar and Uttar Pradesh reported $24.4 \%$ and $20.2 \%$ growth of population during last decade and accounted nearly $25 \%$ of India's population. But when we look in terms of per capita NSDP Maharashtra is quite better with 61,468 rupees per capita NSDP, Andhra Pradesh is at the middle position with Rs 42,589, and West Bengal is having Rs 32,164 NSDP per capita. But, 
Bihar and Uttar Pradesh is at the bottom in ranking with Rs 13,149 and Rs 17,980 NSDP per capita respectively (RBI Handbook 2014). More over it is important to mention that Bihar and Uttar Pradesh are facing the problem of mass poverty which is around thirty to thirty four percent of their population (Poverty Estimates 2011-12).

\section{Fertility and Mortality Indicators}

There is a wide gap between Crude Birth Rate (CBR) and Crude Death Rate (CDR) of the country. As per the census 2011, the total CBR value is 21.8 whereas CDR value is 7.1 showing a gap of 14.7 . It means there is a net addition of 15 persons for per thousand populations to the total population annually. The census 2011 also reveals that birth rate of rural area is 32.3 which is higher than urban area having 17.6 birth rate. Similarly death rate of rural area is 7.6 which are higher than urban area having 5.7 death rates. Among the bigger states birth rate of Uttar Pradesh is 27.7 where as it is 27.4 for Bihar. This is a serious concern for these two states considering their 29.43 and 33.74 poverty percentage respectively and low level of per capita income (Annexure-I).

\section{Literacy}

Literacy is a backbone of a country for its progress in all dimensions. But still we are far below in achieving the desired one or which we should have. As per the definition of census 2011, India's literacy rate is $73 \%$; which shows an increase of 8 percent points over the literacy in 2001. Differentiating the decadal change among Male-Female it is observed that male literacy has increase around six percent points and currently it is $80.89 \%$; whereas female literacy has increased by eleven percentage points and become $64.64 \%$ over last census. Though there is improvement in the literacy of both the sexes the literacy in women is less than literacy in men which shows the male -female literacy gap of 16.25 percentage points. Bifurcation of literacy as per the residence, it is observed that there is a large gap of 16.34 percentage points in rural urban literacy, where rural literacy is $67.77 \%$ and the urban literacy is $84.11 \%$. The observed change over the last census shows that 
rural literacy has increased by nine percent points and urban literacy has increased by only four percent points.

The increase in literacy percentage is only one side of the coin, but the other side shows that there are more than 40 crore illiterate persons, which is around equal to the population of four high populous states of country (Uttar Pradesh, Maharashtra, Bihar and West Bengal). Despite the narrow definition and dozens of literacy programs and schemes, the gap between rural-urban and malefemale literacy has remained high. The situation of bigger states shows that only $67.68 \%$ persons are literate in Uttar Pradesh and worst case is $61.8 \%$ literacy in Bihar.

\section{Sex Ratio}

The distribution pattern of male and females can effect on the social and economic activities of the nation. Sex Ratio is useful to look at gender equality or to identify the gender biases among the cross section of regions. As per the census data India's sex ratio in 2011 is 943 females per thousand males; which shows ten point increase over 933 sex ratio in 2001. During this decade rural sex ratio has increased by only three points from 946 to 949 , but the good thing is depicted in the form of improvement in urban sex ratio from 900 in 2001 to 929 in 2011 . The overall sex ratio is a rough measure of gender differences. More clarity can be obtained by looking at sex ratio for age group 0 to 6 years. Sex ratio of 0 to 6 years age group indicates that this ratio has fallen from 927 to 919 during last decade. The urban sex ratio remained at 905 whereas it was 906 in 2001 but the rural child sex ratio has fallen to 923 from its previous value of 934 . Overall sex ratio of bigger states shows that Uttar Pradesh, Bihar and Maharashtra are having lower sex ratio than national average and for Child sex ratio Maharashtra and Uttar Pradesh are below than national average of 919 (Annexure-1).

\section{Age Composition and Dependency}

By age composition we mean to focus on the productive capacity of the nation. For India as per census 2011 the quantum of working age population is very high. As per the definition of census of India, population in age group 15 to 59 years is called 
'economically active population'; alternatively it is a 'working age population'. The portion of this age group in total population is around $62 \%$. Working age population in urban area is found higher than rural area (Figure 1.1). The number of persons having age between 0 to 14 years are called 'young dependents' which account nearly 30 percent of India's total population; whereas persons aged 60 and above are the 'old dependents' which accounts $8 \%$ of the total population.

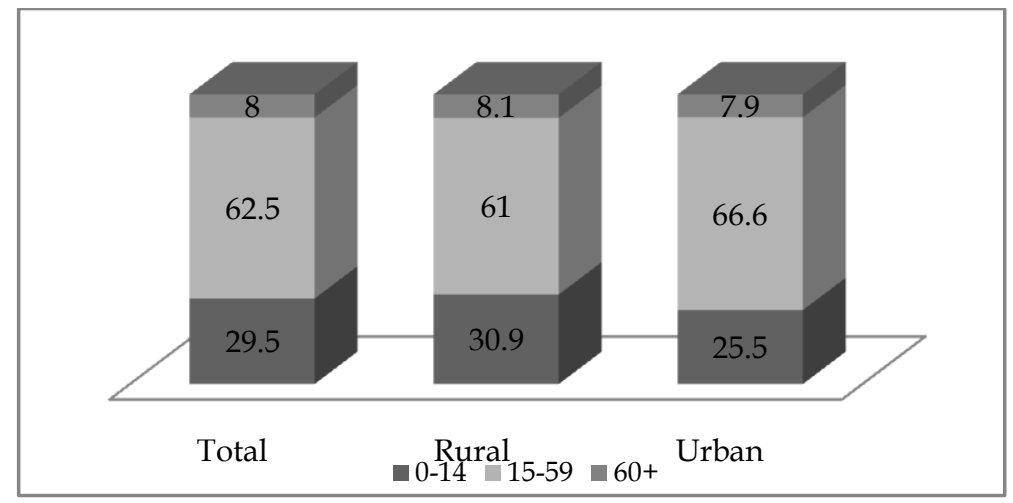

Fig 1.1 Age Composition of India (2011)

Source: Census 2011

Dependency ratios indicate the situation of social support needs. A high dependency ratio means there is a large burden of economically inactive population on the economically active population and on the overall economy. Currently, the overall dependency ratio for India is $65 \%$. The separate dependency ratio for young dependents is $51 \%$ whereas the old age dependency ratio is $14 \%$. Economically speaking, the higher population in the age group below fourteen years is the young dependents today; are the potential workers for tomorrow. The quantum of young dependents in rural area is (31\% of total rural population) higher than urban area (26\%). The reason of this could be linked with high birth rate in rural area than in urban area.

\section{India's Demographic Transition}

As per the trend of Crude Birth Rate (CBR) and Crude Death Rate (CDR) India is in the third stage of Demographic Transition (DT) 
where we find CBR and CDR both declining. The first stage of DT was a stage of pre-independence say up to the year 1921. In the second stage of DT and after independence CDR has fallen rapidly from 27.1 during 1950-55 to 13 during 1975-80 whereas CBR has fallen very slowly from 43.8 during $1950-55$ to 35.9 during 1975-80. So the rapid fall in CDR and comparatively slow fall in CBR resulted in increasing population growth. So, the point of high natural growth rate is the end point of second stage and starting point of third stage. In the third stage death rate has fallen very slowly till 2010-15, and then onwards death rate will increase while the fall in birth rate will continue. This trend will carry forward till 2065-70 where CBR and CDR become equal to each other. This will be the end of third stage and beginning fourth stage of demographic transition. In this third stage population is continuously increasing with falling but positive growth rate. This stage takes very long period to end where CBR and CDR become equal. As per the United Nations Population Projections, India's population in 2065 will be at its peak with more than 164 crore persons. Further in fourth stage country's natural growth of population will be negative and total population of India will fall (Figure 1.2).

In the above figure the trend of birth rate and death rate and natural growth rate of population is given for 150 years from 1950 to 2100 .

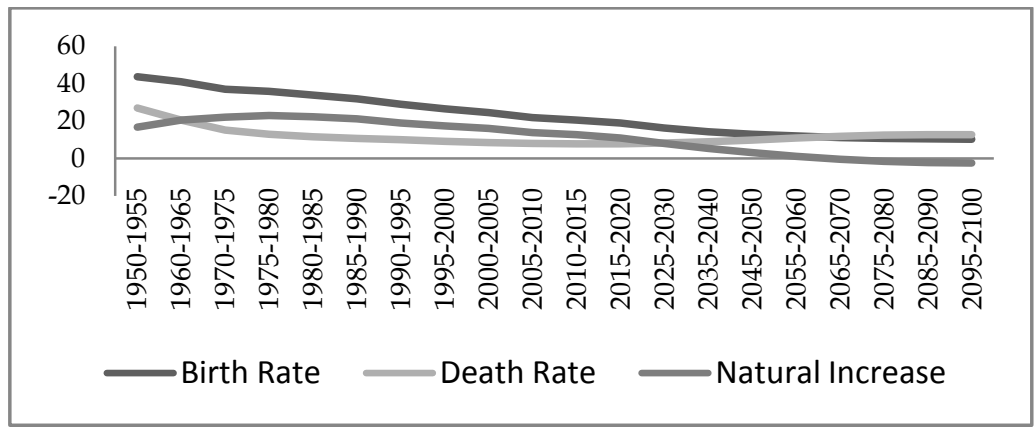

Fig 1.2 Demographic Transition in India.

Source: United Nations Population Division (Revisions of 2012) 


\section{India's Demographic Dividend: an opportunity}

As defined by the United Nations Population Fund (UNFPA), "the economic growth potential that can result from shifts in a population's age structure, mainly when the share of the workingage population (15 to 64 ) is larger than the non-working-age share of the population (14 and younger, and 65 and older)."

As mentioned earlier, the working age population is also known as 'economically active' population. If country provides work for each hand in the working age group, there will be large economic gains. To attain the gains country must investments in youths; particularly for health and education to foster skilled and healthy labour force. By strengthening health programs country can get healthy adults who can contribute more significantly to economic growth. Through educational programmes young people can be skilled to take on higher-quality jobs in a changing and growing economy. Through these investments labour force would be equipped to reap the opportunity of demographic dividend. For India as per the census working age population is considered as the total population between age group 15 to 59 years.

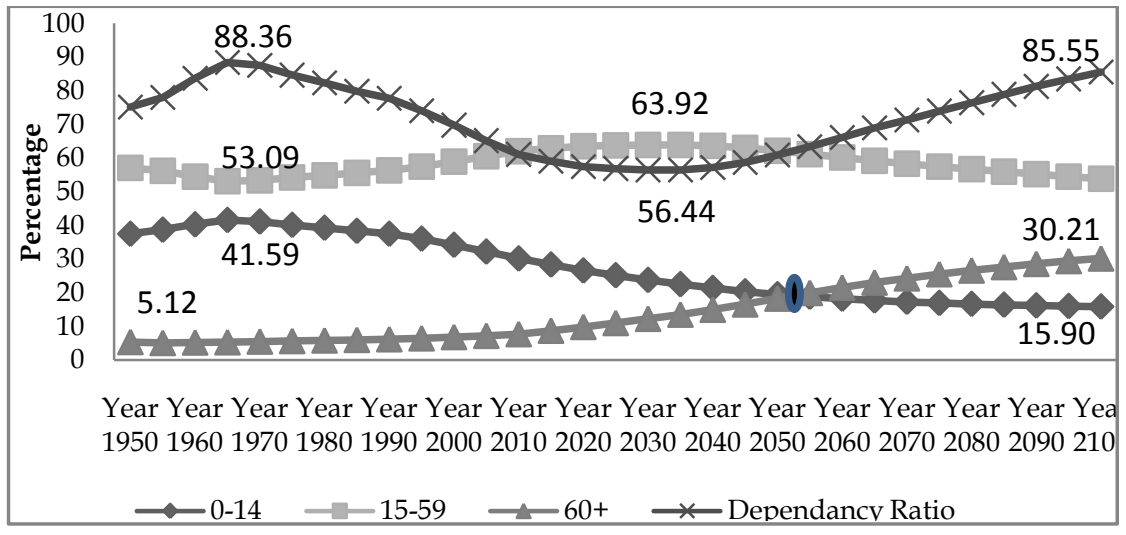

Fig 1.3 Trend of Working Age Population and Dependency Ratio (1950 to 2100)

Source: United Nations Population Division (Revisions of 2012)

So considering this age group, as per the UN population projections for 1950 to 2100 it is found that the trend of working age population is continuously increasing since 1965 and it will be at its peak by 2030 with nearly $64 \%$ of economically active population. 
For the same year dependency ratio will be at its lower point with $56.44 \%$. This indicates that for every ten working age persons there are nearly five to six dependants.

Looking at the future demographic profile of India, it is clear that, India will experience a long phase (of forty to fifty years) of Demographic Dividend. So the dividend period is a window of opportunity. This opportunity is highly depends on how our youth can acquire skills and seize the domestic and global employment opportunity in the future. This implies that there would be large and growing labour force, which can be expected to deliver large scale spin-off in terms of growth and prosperity.

It is important to note from the above figure that, after 1930 the dependency ratio will tend to increase and there will be shift in the share of dependents from young dependents to increase in old dependents. It is also observed that, during 2050 to 2055 share of young and old dependents will be equal to each other and after that share of old dependents will increase and young dependents will tend to remain constant. This change in age structure will have different economic implications. So, a more rigorous explanation on the age and sex composition is given in the following paragraphs, by giving easy visual presentation with the help of population pyramid.

\section{Changing Age composition}

The following four figures are showing changing age and sex composition of Indian population from 1950 to 2100. The age composition of 1950 shows dominance of young (pre-reproductive population of 0 to 14 years) population and very small share of old (post-reproductive of $60+$ years) population. Alternatively saying this phase is a phase of baby boom. A pyramid with broad base and tapering to the top indicates the rapid growth of population which is a common feature of developing nations. As shown in the following figure composition of 1950 is showing high population growth. Further this composition has changed in 2010 which shows falling growth rate, whereas pyramid of 2050 shows rapid fall in population growth. This is due to increasing death rate and falling birth rate. In this phase broader cohorts of pre reproductive population are moving to reproductive population and middle size 
cohorts of reproductive population are moving to post reproductive age group. This can be observed by the expanding portion at the top of pyramid. Further the cohorts moved from pre reproductive to reproductive age group will move to post reproductive age group. This can be observed by the pyramid of 2100, which shows more stretched cohorts at the top which indicate improved life expectancy of the country. The base of the pyramid is narrowing as a result of negative growth of the population due to higher death rate than birth rate (figure 1.2).

1950

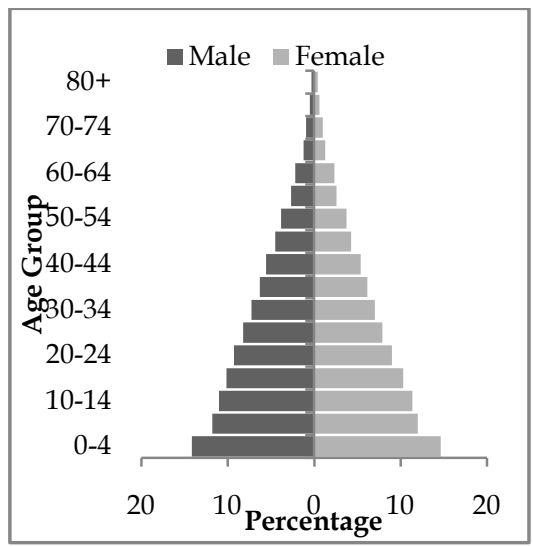

2050

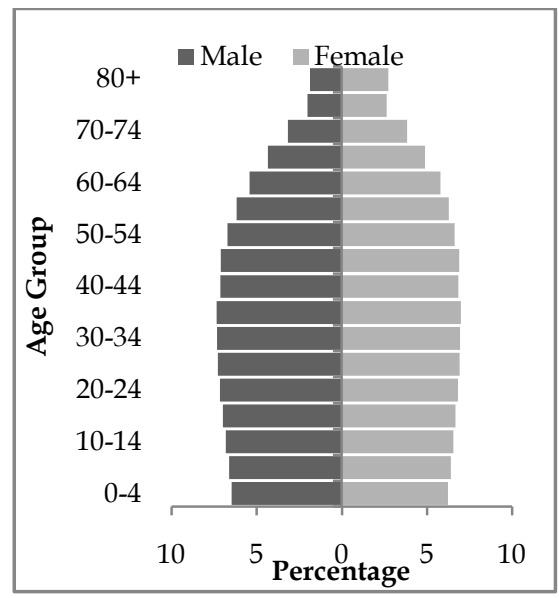

2010

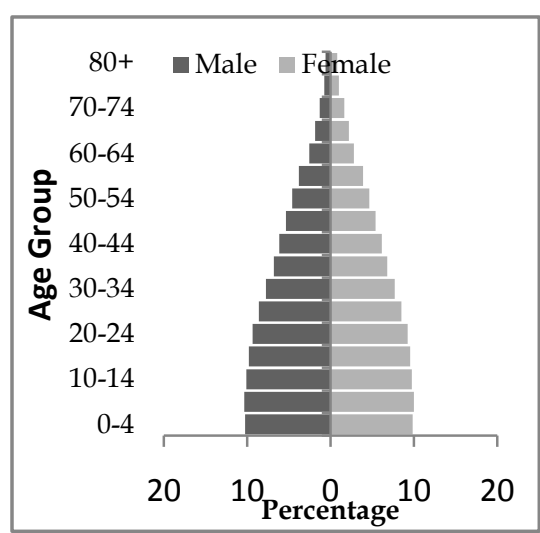

2100

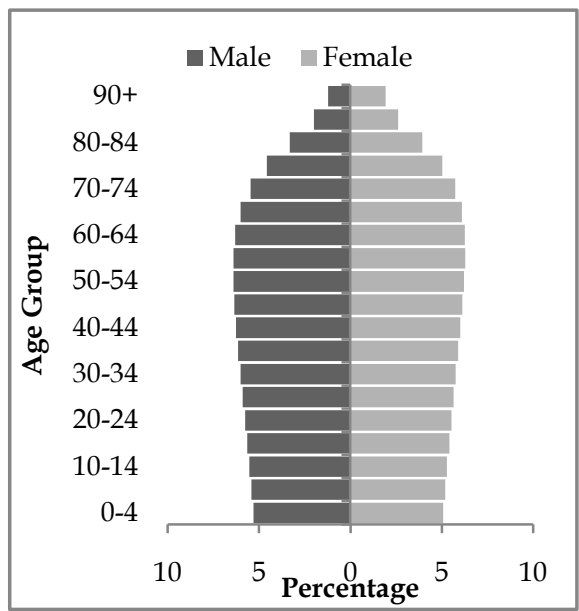

Fig 1.4: Population Pyramids for India (Year 1950, 2010, 2050 and 2100)

Source: United Nations Population Division (Revisions of 2012) 


\section{Economic Consequences of the Changing Age Composition}

The economic consequences of changing age composition are different for different age composition, like in a stage of baby boom as shown in the pyramid of 1950 more resources are required for primary needs such as food, clothing, housing, schooling and medical care. Further, when the babies born in such a boom will invariably reach at its working age (Pyramid of 2010), more resources are required to invest in job creating sectors such as agriculture, industry and service sector. The investments in job creating sector will expand the productive capacity of the economy and the demographic dividend can be obtained. The pyramid of 2050 indicates the need for job creating investment as well as investment needs for social justice (to provide for increasing old age population). The pyramid of 2100 indicates more requirements of social justice, because more old age persons will be observed in this state due to improved life expectancy problem of ageing is faced.

\section{Population Ageing}

The phase of population ageing is taking place in nearly all the countries of the world. Ageing results from decreasing mortality, and, most importantly, declining fertility. This process leads to a relative reduction in the proportion of children and to an increase in the share of people in the main working ages and of older persons in the population. The global share of older people (aged 60 years or over) increased from 9.2 per cent in 1990 to 11.7 per cent in 2013 and will continue to grow as a proportion of the world population, reaching 21.1 per cent by 2050 (World Population Aging, 2013). For India share of older person in total population has increased from 5\% in 1950 to $8 \%$ in 2010, further it is projected to reach at $18.34 \%$ in 2050 and $30 \%$ in year 2100 . 


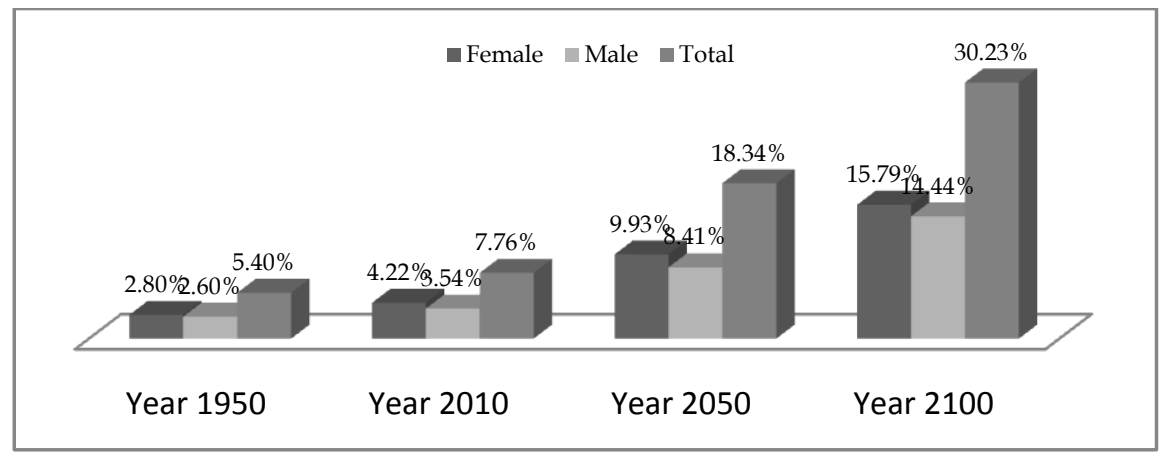

Fig 1.5 Percentage of Old Dependents

Source: United Nations Population Division (Revisions of 2012)

Older persons are projected to exceed the number of children for the first time during 2050-55. The trend shown in the above figure indicates that out of total older population share of females will be increased than male throughout the period. The increasing number of older females (old dependents) indicate the improved life expectancy of females than males. This indicates the need for gender specific support system for coming time period.

As mentioned above changing demographic composition has its different economic consequences and it has social consequences too. India the world's second large country today, getting benefits from its large economically active population. But it has many challenges for future period. So the followings discussion will point out the challenges ahead.

\section{Challenges Ahead}

In India distribution of population is diverse and it has created many socio and economic challenges. Some of the challenges are listed as under.

First, the challenge of reducing high birth rate and poverty percentage in states like Bihar and Uttar Pradesh, because reducing numbers of poor people in bigger states is difficult than reducing it in comparatively small populous states.

The increasing population in bigger states has created burden on the distribution for social welfare schemes such as providing 
education for all. Though India implemented many schemes for providing education, the literacy rate of Bihar, Andhra Pradesh and Uttar Pradesh is still below the national average and these three states accounts around one third population of Country (AnnexureI). So providing literacy for mass population in bigger states is truly a challenge.

Improving the overall sex ratio and child sex ratio in states having low sex ratio like Bihar, Uttar Pradesh and Maharashtra is a third challenge.

India is experiencing high and increasing trend of working age population which will last by 2030. After that this trend will decline. So the challenge is to provide appropriate policy for productive absorption of the growing working-age population especially heavy investment in human capital formation is required.

It is observed that in India old dependents are expected to increase (population ageing) in the coming decades which will have major social and economic consequences. The population ageing ensures the fiscal pressures on support systems for older persons. In a number of developing countries, poverty is high among older persons, especially in countries having limited coverage of social security systems. So, providing a social security system for a large portion of older persons is a challenge for coming time.

\section{Conclusion}

To conclude, while going through demographic transition, India and the states are facing diverse demographic situations. There are opportunities and challenges too. In the bigger states like Bihar and Uttar Pradesh there is a high population and low per capita income causing to mass poverty. Poor condition in these states leads to high birth and death rates. It has seen that lower literacy and low sex ratio are the allied aspects of Indian economy and especially for bigger states.

Apart from this pessimistic picture, a ray of optimism has seen in the age composition of country as a whole and for bigger states too. The age composition having more working age population is 
expected to continue for next one and half decade. So lower dependency and high economically active population is an opportunity to boost India's growth process. But without appropriate policy formulation it cannot be achieved.

Apart from this if we observe the projections on future age composition of the country we found that there is an increasing trend of dependency ratio. This will be the upcoming challenge for policy makers. So this paper indicates the need for long term population policy formulation to reap the demographic opportunity and to provide mechanism for future challenges.

\section{References}

Bhat, P.N.M. (June, 2001). Indian demographic scenario 2025. Retrieved from http://planningcommission.nic.in/ reports/ sereport/ ser/ vision2025/demogra.pdf

Handbook of Statistics on Indian Economy. (2013-14). Retrieved from https://rbidocs.rbi.org.in/rdocs/Publications/PDFs/ 000HSE13120914FL.pdf.

Haub, C., \& Sharma, O. P. (2006). India's population reality: reconciling change and tradition. Population Bulletin, 61(3), 1-20.

Lonarkar, P. P. (2011). India's demographic dividend. Ashwattha, 5(3), (JulSep), 2-8.

Mujumdar, P. K. (2013). India's demography: Changing demographic scenario in India. Jaipur: Rawat Publications.

Newbold, K.B. (2012). Population geography: Tools and issues. Jaipur: Rawat Publications.

Press Note on Poverty Estimates 2011-12. (July, 2013), Retrieved from http:// planningcommission.nic.in/news/pre_pov2307.pdf.

Ram, U. Changing age composition of population of India, Indonesia and Thailand: Health issues of elderly. Retrieved from web link:http://archive.iussp.org/Bangkok2002/S17Ram.pdf.

United Nations. (2009). World population prospects: The 2008 revision, Highlights, (Working Paper No.ESA/P/WP.210). Retrieved from web link: http://www.un.org/esa/ population/ publications/ wpp2008/ wpp2008_highlights.pdf.

United Nations. (2013). World population ageing 2013, (Report No: ST/ESA/SER.A/348). Retrieved from http:// www.un.org/ en/ 
Artha-Journal of Social Sciences, Vol.17, No. 2

development/desa/population/publications/pdf/ageing/WorldPop ulationAgeing2013.pdf. 